\title{
THE LONG TWENTIETH CENTURY \& THE CULTURAL TURN: WORLD-HISTORICAL ORIGINS OF THE CULTURAL ECONOMY
}

\author{
Benjamin D. Brewer, PhD \\ Assistant Professor of Sociology \\ James Madison University \\ brewerbd@jmu.edu
}

\begin{abstract}
In this essay I link Giovanni Arrighi's world-historical framework in The Long Twentieth Century to debates about the "cultural turn" in global capitalism since the 1970s. I do so primarily through interrogation of the writings of one of the major figures in such debates: Fredric Jameson. In his Jameson's engagement with Arrighi's, he emphasizes the determinative influence of finance capital on an expansion in the degree of cultural abstraction and fragmentation that is emblematic of the post-modern condition. Building on this linkage, I extend and elaborate Arrighi's analysis of historical capitalism's cycles of accumulation, in which periods of material expansion give way to phases of financial expansion and accelerated restructuring of the organizational and institutional foundations of the world-economy. I conclude that Jameson's assertion of a link between the financialization of the world economy and post-modern cultural forms is best understand as a correlative rather than a causal relationship, for the growing salience of finance capital and the new forms and degree of cultural abstraction are themselves both dimensions of the more fundamental socio-economic restructuring attending a period of financial expansion.
\end{abstract}

\section{INTRODUCTION}

My aim in this essay is to explore the possibilities for a creative synthesis between the worldhistorical economic sociology pioneered by Giovanni Arrighi (1994, 2007; Arrighi and Silver 1999) and the post-structuralist concern with the "cultural turn" in the history of global capitalism since the $1970 \mathrm{~s}$. In turning to one of contemporary social science's most nebulous signifiers, "culture" (a slippery slope), I resist the temptation to do everything at once. Instead, I focus on the increasingly important role of the commercialized production, distribution and consumption of images, brands, and popular culture in leading sectors of the core economies. Why strike these two, seemingly antagonistic, perspectives together to begin with? Perhaps, to mix some metaphors, so that the resulting sparks might ignite the straw men from each - the purportedly deterministic political-economy approach and the cultural studies perspective's (over)emphasis on acts of agency and resistance -- and in so doing, light the path to an analytically productive account of contemporary socio-economic change. Or, following Arrighi's great methodological injunction, because this should help in distinguishing just what is cumulative, what is cyclical, and what is truly new about present cultural and economic change. 
Even in the wake of a hyperbolic decade in which the "new economy" discourse came and went, pronouncements of the unique, historically unprecedented or epoch-making transformations in culture, commerce and society are not hard to come by. So, this is a path worth following not only because of the truism that we now live in an age of "informational" or "cultural" capitalism (Bell 1973; Castells 2000a; DeBord 1995 [1967]; Lash and Urry 1987, 1994; Poster 1990; Webster 2002) - even if this claim is more than worthy of interrogation in its own right. Rather, this is equally important because so many empirical studies in globalization studies themselves point to the importance of culturally-inflected, "intangible" economic activities (e.g. branding, design, marketing, retailing) in maintaining competitive advantage for firms, and nations, in the contemporary global division of labor (Aspers 2010; Bair and Gereffi 2001; Coe 2004; Coe and Hess 2005; Dolan, Humphrey and Harris-Pascal 1999; Gereffi 1999; Hughes 2000, 2007; Hughes, Wrigley and Buttle 2008; Jernigan 2000; Klein 2000; Korzeniewicz 1994; Pratt 2008) For instance, from some of the leading scholars in the global commodity chains perspective we hear that:

Many 'lead' firms have narrowed their focus to product development and marketing while outsourcing production and production-related functions to suppliers... Much of this shift can be captured by noting the increased cost and importance of activities that deal with intangibles, such as fashion trends, brand identities, design and innovation, over activities that deal with tangibles, the transformation, manipulation and movement of physical goods (Gereffi et. al., 2001: 33, emphasis mine).

Likewise, "brands play an increasingly important role in enterprise strategy" (Humphrey \& Schmitz 2001: 26), in as much as brands "which can be created without proprietary links to specific manufacturers or distribution channels" (Gereffi et. al. 2001: 33) are now seen as a major source of market power.

In what follows, I sketch out the ways that Arrighi's analytical framework can be repurposed to speak explicitly to these developments, which are frequently held up by cultural studies analysts as evidence for the growing centrality of intangible, cultural knowledges within contemporary economic life. Although The Long Twentieth Century seems to have little to say about the core concerns of the cultural studies project (broadly construed), this silence does not derives from an inherent theoretical antagonism. Arrighi offers a set of insights into the shifting organization of business enterprise and leading sectors of the capitalist world-economy that can yield fresh insights into the developments associated with the "new" or "cultural" economy. I therefore rely on Arrighi's notion of "financialization" of the world economy, but not merely as a measure of the increasing volume or influence of finance capital, tout court. A fuller reading of his analysis underscores that financialization itself cannot be understood without reference to the broader set of social, political and economic transformations by which historical capitalism has been restructured and reorganized on progressively larger scales over time - a process in which financialization serves as consequence as much as cause. It is within these dynamics that the forces impacting commercialized cultural production are generated, institutionalized within particular organizational arrangements, and ultimately transformed as well. 


\section{JOURNAL OF WORLD-SYSTEMS RESEARCH}

\section{PART I: INTERROGATING THE NEW/CULTURAL/INTANGIBLE ECONOMY}

A series of somewhat systematic internet searches for the LTC and its association with various terms, topics and phrases yielded a surprising (to this author, at least) finding: The Long Twentieth Century is linked with nearly as many online syllabi, conference proceedings, and webbased discussions within the domains of comparative literature, critical theory, and cultural studies as it is to those from international political economy and world-systems analysis. Without making too much of such a rough-and-ready survey, the basic finding is nonetheless noteworthy. For, despite Arrighi's intellectual and personal association with the world-systems tradition - not to mention the paucity of explicitly "cultural" analysis in the book itself - The Long Twentieth Century seems to have gained a good bit of traction within cultural studies.

In this section, I address one of the emblematic ways that Arrighi's work has been read by critical cultural studies. I do so primarily by interrogating Fredric Jameson's engagement with Arrighi's work, particularly The Long Twentieth Century. Jameson is best known for his writings on postmodernism as the "cultural logic of late capitalism." In this work $(1984,1991)$, Jameson intervened in the then-intensifying debates surrounding postmodernity with a fundamentally materialist analysis of postmodern culture. Jameson's notion of the postmodern condition and postmodern culture centers on its fragmentation, depthlessness and lack of historicity and affective potency (Roberts 2000: 133). Broadly speaking, the postmodern for Jameson is a condition of increased social and cultural abstraction, marked by pastiche - an empty mimicry separated from the ironic and detached voice of modernist parody - and schizophrenia - denoting a sort of breakdown in the process of signification leading to a discontinuity and ultimate incoherence in the meaning of images and texts (Homer 2000: 180-183). As such, cultural texts themselves (film, writing, advertising and so forth) come to embody this postmodern condition in their further abstraction from realist - or even modern - meanings grounded in time and space.

Jameson's deployment of The Long Twentieth Century builds upon this earlier work, and hinges on the increasing abstraction of postmodern culture unleashed by the expanding role of finance capital within the world economy. Reprising his earlier work, Jameson argues that modernism as a cultural and aesthetic shift in the late- $19^{\text {th }}$ century was fueled by the proliferation of new social forms of abstraction (Homer 2002; Roberts 2000). Modernist abstraction, which worked against the realism it ultimately supplanted, derived from the social dislocations associated with industrialization and urbanization in the nineteenth century - the "effects of money and number in the big cities of nineteenth-century industrial capitalism" (Jameson 1998: 143) - along with the shifting relationship between capital, labor and commodities. Money, in its role as universal equivalent of value and exchange, pushed the representation of social reality toward further abstraction. The growing mass of consumer commodity items, with their own material qualities and functional utilities, were increasingly evaluated only in relation to other commodities through their abstract monetary exchange value; unique craftspeople, knowledge and skills were likewise transformed by the more abstracted notion of "labor power" via the monetary wage. Modernist abstraction was therefore a function of "money itself in a situation of capital accumulation."

Money is here both abstract (making everything equivalent) and empty and uninteresting, since its interest lies outside of itself....it directs attention elsewhere, beyond itself, towards what is supposed to complete (and also 
abolish) it, namely production and value. It knows a semi-autonomy, certainly, but not a full autonomy in which it would constitute a language or a dimension in its own right (Ibid.: 160-161).

The financialization of capitalism brings a related shift in abstraction - effectively ushering in the postmodern condition - for Jameson sees financialization as "a play of monetary entities which needs neither production (as capital does) nor consumption (as money does): which...can live on its own internal metabolism and circulate without any reference to an older type of content" (Ibid.: 161). In other words, an even more refined form of cultural abstraction emerges as "capital itself becomes free-floating," and detached "from the "concrete context' of its productive geography" (Ibid.:142). While money may have increased the degree of abstraction predominant in the perception and representation of social life during the "productive" moment of industrial capitalism across the mid $-19^{\text {th }}$ to late- $20^{\text {th }}$ centuries, it nonetheless remained partially grounded, Jameson argues, in its material origins, as "cotton money, or wheat money, textile money, railway money and the like" (Ibid.: 142). With the growing predominance, in the late twentieth century, of financial means of capital expansion and accumulation came an intensification of social and cultural abstraction, for "money capital [had] reached its ultimate dematerialization, as messages which pass instantaneously from one nodal point to another across the former globe, the former material world" (Ibid.: 154). Put simply, money, always a force for abstraction under capitalist production and exchange, is even further un-tethered from the social relations of capitalist production during a phase of financial expansion. Alongside these changes comes a related shift in the forms, or degree, of abstraction in cultural production and the representation of social life.

It is worth noting here that Jameson's argument, while distinctive in its own degree of abstraction, is not unique. Indeed, clipped and shorn of its more obtuse passages and claims, the core of Jameson's argument linking finance capital to a less materially-grounded, more intangible and abstract set of cultural and social forms, sounds quite similar to some other influential macrolevel treatments of the economic and cultural dimensions of our times. For instance: Manuel Castells' (2000a, 2000b, 2004) sprawling analysis of the "information age" in which he asserts that the rise of a "new economy" - centered on the production, distribution and consumption of intangible and dematerialized information - has driven transformations in social organization and relations. The network, in his view, is the paradigmatic organizational form of the information age; flows of information and finance capital through technology-enabled global networks are now the most salient determinants of social and economic development. Yet, finance capital - or "financial flows" - is so central to Castells' framework that it becomes difficult to analytically distinguish the presence of a globally integrated financial system from these other elements of the "new economy" and "network society."

Likewise, David Harvey's tremendously influential account of the transition to "postFordism" and postmodernity hinges on the emergence of new forms of small-batch, highly specialized, more "flexible" production firms within the interstices of a global industrial structure constricted by the rigidities of Fordist mass production and consumption, and the inherent contradictions of this system's expansion to a growing proportion of the world's population. Still, deep into the analysis, Harvey says: 


\section{JOURNAL OF WORLD-SYSTEMS RESEARCH}

What does seem special about the period since 1972 is the extra-ordinary efflorescence and transformation in financial markets...I am therefore tempted to see the flexibility achieved in production, labour markets, and consumption more as an outcome of the search for financial solutions to the crisis-tendencies of capitalism, rather than the other way round. This would imply that the financial system has achieved a degree of autonomy from real production unprecedented in capitalism's history (1990: 194, emphasis mine).

In sum, we encounter in all these perspectives a shared sense that an understanding of finance capital is crucial to any analysis of contemporary social change. Yet, for all three, there is a general analytical discomfort in actually incorporating financialization into an analysis of social change within the world-system of the late $20^{\text {th }}$ and early $21^{\text {st }}$ centuries. In all of these treatments ${ }^{1}$ - to varying degrees and for somewhat different reasons - we also encounter a sense that the growing weight of finance capital is in some way connected to an expansion in the "cultural" dimensions of economic activity, a shift toward a more "intangible" or "immaterial" global economy, and an increasingly abstract cultural and socio-political realm.

\section{Getting Empirical with Jameson}

Jameson posits an intriguing connection between cultural abstraction and finance capital, but, on its own, the argument offers very little immediate direction to more empirically-grounded analysis. In Jameson's own phrasing (1998: 146), his analysis is "epochal" in its ambition -it specifies a relationship at many levels of abstraction from concrete space and time. Certainly close analysis of various cultural texts could help us establish that these new forms of expression and abstraction exist and can be observed and delineated. However, the path is less clear to those of us seeking to understand how financialization is concretely and causally linked to what we might call the "production of abstraction" by specific agencies, actors and organizations." Jameson provides one possible starting point when he argues:

[A]ny comprehensive new theory of finance capitalism will need to reach out into the expanded realm of cultural production to map its effects: indeed mass cultural production and consumption themselves... are as profoundly economic as the other productive areas of late capitalism, and as fully integrated into the latter's generalized commodity system (1998: 143-144, emphasis mine).

This actually closely follows the argument Jameson made as part of his seminal essay on postmodernity:

\footnotetext{
${ }^{1}$ And we could add Lash and Urry $(1987,1994)$ to this list as well.

${ }^{2}$ Here I would appear to agree with Sean Homer when he notes that, "what this work [of Jameson's] lacked... was any systematic account of the mediations between the individual subject and the world system" (2002: 186).
} 
What has happened is that aesthetic production today has become integrated into commodity production generally: the frantic economic urgency of producing fresh waves of ever more novel seeming goods (from clothing to airplanes), at ever greater rates of turnover, now assigns an increasingly essential structural function and position to aesthetic innovation and experimentation (1984: 56).

In this, Jameson suggests a link between finance capital and the predominance of abstraction in postmodern culture might be found in the production, distribution and consumption of commercialized "popular" culture. Perhaps what is new to late- $20^{\text {th }}$ century (and early $21^{\text {st }}$ century) capitalism is the significance of this "mass cultural production" or, in different words, "aesthetic production/innovation"? Or perhaps under conditions of financialization, the "cultural" dimensions of production and consumption intensify to such an extent that a general shift toward increasing cultural abstraction or intangibility can be identified?

\section{Materialization to Abstraction... and Back Again}

One of the most significant mechanisms by which cultural abstraction and the socioeconomic restructuring of financialization are linked is highlighted by what Don Slater (2000) refers to as the socio-cultural "processes of materialization." Taking aim at the notion that, within contemporary capitalism, "the processes, factors and outputs of economic processes are to be understood - increasingly - in terms of meanings, signs and cultural processes"(Ibid.: 95), Slater instead problematizes the distinction between "sign" and "object." In fact, the object/sign distinction wrongly presumes a natural "physicality" or "objectness" of things, even though the very stability of something as a coherent physical object is itself a socially-constructed property. Put differently, "objectness" itself is also an immaterial "sign" in so far as it must be established through social interaction rather than through some essential, inherent physical quality of the object itself - a relational rather an essentialist ontology. The "materiality" of objects and activities is actually produced by the relative stability of the link between an object and the meaning attached to it as a particular type of physical thing. Slater labels the construction, maintenance, and transformation of these linkages between objects and physical definitions as the "processes of materialization."

The process of materialization is clearly foundational to market and trading activity, best illustrated by our routine discussion of the "market" for a particular commodity - the "cell phone" market, the "car" market and the like. In this conventional usage, there is an assumed stability to the material definition of the item in question - there is a clear definition of what this object is, how it works, what it does and how it provides a particular utility. What is more, by invoking a "market" for this commodity we assume that competing versions released by different producers are ultimately substitutable items. ${ }^{3}$

\footnotetext{
${ }^{3}$ For example, we discuss the market for "home computers" and presume a fixed set of capabilities - the "meaning" of the commodity based on the utility it offers (e.g. word processing, financial management, web browsing) - provided by a concrete combination of material objects (e.g. monitor, cpu, keyboard). A Dell can be compared with, and substituted for, an Apple, HP or Lenovo for these are all fixed commodities available to consumers in the "computer" market.
} 


\section{JOURNAL OF WORLD-SYSTEMS RESEARCH}

There are two problems with this, however. For one, there are actual technical changes in the nature of most commodified objects that imply new utilities and functions and thus disturb their fixed "material" identity over time. Secondly, and more importantly, the material stabilization of commodities is itself an important dimension of the competitive process for firms and market actors. ${ }^{4}$ Over time, capitalist competition thus disrupts and reworks the provisional stabilization of "material" product identities. Today:

Economic actors - functionally differentiated into institutions such as advertising, brand consultancy, design - may place the conjoint redefinition of goods and markets at the very center of market practices: marketing, for example, is specifically dedicated to altering relations of sameness and difference for competitive advantage. Far from competition presuming the stability of things, destabilization is central to conceptualizing and conducting competitive strategies (Ibid.: 98, emphasis mine).

To be clear, the processes of materialization have always been unstable and dynamic; pre-capitalist market exchange required the stabilization of goods and categories just as much as contemporary capitalist market activity does. In this sense, the processes of materialization are a longstanding, even universal, fact of human socio-economic activity. What can change over time is the relative importance of materialization activities for securing competitive advantage in the accumulation of capital. In this respect:

What is 'new' today...concerns the extent to which the process of materialization... has become reflexively institutionalized and instrumentalized as a premise of economic action and organization. We can re-describe vast areas of corporate and consumer behavior in terms of [materialization/dematerialization] in the interests of either competitive gain or cultural reproduction. Put this way, we open up the historical question of what new social conditions have opened up that historical path (Slater, 2002: 103, emphasis mine).

Thus, the oft-asserted 'dematerialization' of contemporary capitalism and the growing importance of cultural or image-based factors within contemporary capitalism do not diminish the physicality of goods. Instead, we are witnessing the increasing intensity and scale of de/rematerialization processes driven by market actors who increasingly see such activity as a source of competitive advantage. As Slater indicates, explaining variations in the organizational institutionalization and increasing intensity of this competition requires consideration of deeper socio-historical dynamics (for example) that give rise to these "new social conditions." Arrighi's historical framework allows us to take Slater's guiding thread and elaborate these dynamics of

\footnotetext{
${ }^{4}$ Returning to the "home computer," the advent of high speed networking, massive increases in storage capacity and processing power have all contributed to a longer-run shift in capabilities and the material framing of computing devices. For example, is the home computer now a personal entertainment device, a multimedia "hub," a communications device? Indeed, Apple - the "computer" now scrubbed from its trademark - has famously specialized in the redefinition of computing device categories
} 
materialization, the increasing prominence of advertising and brand-creation, and financialization into a provisional model.

\section{PART II: SYSTEMIC CYCLES OF ACCUMULATION \& MATERIALIZATION}

For Arrighi, phases of capitalist development are conceptualized as "systemic cycles of accumulation." These cycles are characterized by an initial period of material expansion of the world economy, enabled by the production and effective maintenance of geopolitical order by a hegemonic state, followed by an era of financialization. Material expansions have been founded on the relatively stable expansion of an integrated world-economy centered on leading sectors in which the hegemon specializes. Eventually, material expansion has given way to decline and crisis: of profitability within the world economy, and of legitimacy for the hegemonic state. This crisis tendency, however, has normally been partially forestalled and reversed in the "core" economies - and, most significantly, the declining hegemon's - through the widespread retraction of capital from the material economy and a concomitant turn to finance as the leading line of capital accumulation. Arrighi labels this second, and terminal, period of a systemic cycle of accumulation, financial expansion. Like material expansion, financial expansion has inherent limits. Economically, specialization in the successful management of a global oversupply of finance capital in the absence of a sufficient supply of profitable material outlets for such investment ultimately proves self-defeating. Geopolitically, the costs of maintaining global order and the necessary legitimacy required for successful governance become increasingly untenable for the declining hegemon - particularly in the context of an increasingly incoherent and unstable world economy.

From this vantage point, financialization - accompanied by the neoliberal resurgence, or what Philip McMichael (2007) calls the "Globalization Project" - emerged as a pivotal development in the capitalist world-economy in the early 1970s. What is distinctive about Arrighi's formulation relative to Jameson's adoption thereof is its contention that financialization is best understood as an indicator for the global restructuring of the world capitalist system. Arrighi's conception is, therefore, emphatically not a single, totalizing explanation for contemporary social change. Rather, in Arrighi's scheme of things, financial expansion results from the interpenetrated dynamics of geopolitical competition and hegemonic crisis, intensified inter-capitalist competition and restructuring within the world division of labor, and social unrest (Arrighi and Silver 1999: 30). If these broad dynamics of material expansion, hegemonic crisis and financialization are cyclical phenomena of historical capitalism, the particular configurations they have assumed have by no means been fixed; they are historically specific. Indeed, they are marked by "organizational revolutions" at multiple levels:

In [prior hegemonic transitions], the transformation of one dominant system of business enterprise to another did not proceed along some predetermined path inscribed in an invariant structure. Rather, the transformation occurred through a spatial shift of the system's center and a fundamental change in the way business enterprises related to one another and to governments (Ibid.: 121). 


\section{JOURNAL OF WORLD-SYSTEMS RESEARCH}

For our purposes, the centrality of organizational innovations within firms and markets during the financial expansion and hegemonic transition is particularly germane. The essentially Schumpeterian mechanics of the process are straightforward:

The very success of the leading business enterprises of the hegemonic state in 'monopolizing' high-value-added activities draws new competitors into their path of development. As a result, 'monopolization' becomes costly or impossible. More important, expansion and intensifying competition along the paths that had made the fortunes of the hegemonic states' enterprises create the conditions for the emergence of new and more profitable paths of development that over time lead to the formation of new systems of business enterprise under new hegemonies (Ibid.: 97).

Put simply, the success of the material expansion produces an inherent tendency toward the eventual retraction of capital from these same lines of accumulation, a process that has repeatedly given way to financialization (Arrighi 1994: 313). Of course, the material economy does not disappear; rather, it is subjected to restructuring and reorganization within the primacy of financialization. In all prior cycles of accumulation, this restructuring and reorganization during financial expansion has also helped to lay the foundation for a subsequent material expansion of the capitalist world-economy under the political and economic "leadership" of an emergent hegemonic power.

Global "commodity chain" analysis can illuminate the dynamics of this sectoral and industry-level reorganization in eras of financialization. The commodity chain heuristic allows us to map the variety of capitalist responses to changing structural conditions within and across various domains of an uneven global economy: ${ }^{5}$

The [commodity] chain describes the full range of activities that are required to bring a product or service from conception, through the different phases of production (involving a combination of physical transformation and the input of various producer services), delivery to final consumers, and disposal after use (Kaplinsky 2005: 101).

In this fashion, we can envision the global division of labor at any given moment as the dense network of global commodity chains and their interlocking connections. The key actors within this network of global commodity chains are firms - it is at the firm level where strategic investment and allocation decisions are made within the larger context of competitive pressures and anticipated profitability. Within a capitalist world-economy, the basic logic determining a firm's engagement within and across commodity chains does not shift over time. In any given chain, participating firms will seek to maximize profitability by specializing in the particular

\footnotetext{
${ }^{5}$ Readers familiar with the global commodity/value chain framework will recognize I am avoiding many of the debates within that literature with respect to forms of governance and organizational structure within commodity chains. Such concerns are not immediately relevant to our discussion, where we will use the GCC construct primarily as a conceptual mapping device, not an analytical construct.
} 
activities that, at a given time, are anticipated to yield the highest rate of profit. ${ }^{6}$ While the firmlevel goal of increased profitability may not vary over time, the strategies and activities to realize that goal most certainly do, often significantly. The global "commodity chain" construct therefore helps to trace these dynamic shifts in the global division of labor and the leading sectors of the world economy over time. Using the commodity chain optic and taking Slater's processes of materialization as a fixture of socio-economic action, our task is twofold: to explain how these processes are institutionalized during different periods of historical capitalism, and how their intensity and structural function shift across these periods.

Answering the first question is relatively straightforward. The processes of materialization became structurally central to historical capitalism only through the institutionalization, and ultimate professionalization, of advertising, merchandising, and marketing as distinct fields of economic and professional activity. Daniel Pope (1983), Stuart Ewen (2001 [1976]) and Richard Ohmann (1996) each locate this shift during the late nineteenth century and the early twentieth century, the point at which industrialized production of most consumer durable commodities consistently exceeded existing consumer demand - in so far, that is, as that demand was constrained by prevailing social norms and customs regarding consumption and thrift. Advertising came to be seen by manufacturers as "a strategy to match demand to the conditions of capitalist production required by the new [productive] technologies" (Ewen 2001: 33). In Ewen's phrasing, the rise of the "captains of industry" in the US during the late nineteenth-century brought with it the "captains of consciousness": mass consumption had to be institutionalized as a social practice if mass production was to be profitably absorbed:

The mechanism of mass production could not function unless markets became more dynamic... Now men and women had to be habituated to respond to the demands of the productive machinery. The corollary to a freely growing system of goods production was a 'systematic, nationwide plan...to endow the masses with more buying power,' a freely growing system of consumer production (2001: 24-25).

At the broadest level, then, advertising and marketing worked to establish the necessity of consumption, pushing nascent consumers to increasingly commodify their "needs" and helping them to enumerate, and expand, their material desires. To be sure, the growing reliance on the market for many of the core demands of basic social reproduction was also generated by the larger trends of urbanization and proletarianization and the decline of home-based production (Ohmann 1996: 48-50, 62-72). That the most important U.S. industries in the middle of the $19^{\text {th }}$ century were, in Pope's (1983: 32) words, "processing the nation's abundant raw materials and agricultural products into materials which consumers themselves would then fashion into items of utility - bread from flour, buildings from board, clothing from textiles" is testament to the massive transformations in everyday life that would accompany the process of industrialization in the subsequent decades.

The construction of nationally advertised and distributed brand identities for an increasing number of consumer products - cereals, biscuits, juice and other processed foods, cleaning soaps and household supplies, safety razors and toiletries (Pope 1983: 43-61) - also

\footnotetext{
${ }^{6}$ See Kaplinsky (2005: 62-84) for a systematic discussion of this process using the theory of "rents".
} 


\section{JOURNAL OF WORLD-SYSTEMS RESEARCH}

served an immediate strategic function for many producers. Manufacturers of such products, seeking to integrate their operations vertically (through the formal control and incorporation of multiple stages within the full chain of activities responsible for bringing products to market), came to see brand construction through national advertising as a means to upend the prevailing balance of power as it was distributed across retailers, wholesalers, distributors and manufacturers within these established commodity chains. Most simply, manufacturers of undifferentiated, nonbranded, commodity products - which, in fact, meant most every consumer good within U.S. markets prior to the late nineteenth century - had comparatively little control over the "downstream" activities of wholesaling, distribution and retailing.

When producers made unbranded, unadvertised goods, wholesalers could ignore them, could drive down prices, and could control which items reached the retailers' shelves. Retailers themselves could devote their sale efforts only to products carrying a high margin. Manufacturers' advertising campaigns might remedy this (Ibid.: 79-80, emphasis mine).

By constructing brand identities attached to key products through regional or national advertising - for instance, the "Uneeda Biscuit" brand of soda crackers as opposed to the generic, bulk crackers sold in a general store (Ibid.: 48-50) - might build a brand-consciousness amongst consumers that would require retailers buy and stock branded goods instead of previously unbranded, presumably lower-cost, goods sourced from wholesalers. "Advertising itself served as a partial substitute for vertical integration into retailing," for: If customer demand could make a dealer stock an item, and if manufacturer pressure could make him sell it expeditiously and efficiently, why duplicate effort by investing in a manufacturer-owned retail network? (Ibid.: 82).

Clearly the formalization of advertising, merchandising, branding and marketing activities featured centrally in the establishment of the vertically-integrated corporate form from the outset of what became the U.S.-led material expansion of the twentieth-century worldeconomy. And, from Paul Baran and Paul Sweezy's (1966) seminal analysis of the operation of this material expansion once fully established, we learn how these same activities - which they call the "sales effort" - became essential to the function of a capitalist system dominated by large multi-divisional and multi-national corporations. Baran and Sweezy use the term "monopoly capital" in referring to the dominance of a comparatively small group of corporations that, although not literal monopolists, exerts what amounts to de facto oligopolistic control over the markets in which they are involved. Because vertical integration creates efficiency through the careful management of the flow of an entire production process, disruptive and unpredictable variations in the prices for the final outputs of the process were this system's Achilles heel. In response to this risk, market control under monopoly capitalism was exerted through a tacit arrangement in which price competition was shunned. In an expansionary period dominated by only a few key firms in most markets, this cooperative stance ultimately benefited the small group of participants by avoiding the zero-sum game of price competition (Ibid.: 58-59).

With a taboo against price competition, Baran and Sweezy argue, firms instead turned to innovations within the production process itself - the management and reconfiguration of the "flow" - as the main means by which profitability could be expanded, leading ultimately to a general decline in production costs and a consequent tendency for the total economic surplus to rise (Ibid.: 68-72). This growing surplus, which could not be productively reinvested in the same 
lines of production from which it was derived, therefore needed to be absorbed in some other fashion, with the "sales effort" - "advertising, variation of the products' appearance and packaging, 'planned obsolescence,' model changes, credit schemes, and the like" (Ibid.: 115) being one of the most important such strategies. ${ }^{7}$ In this way, Baran and Sweezy underscore how it is only with monopoly capital and vertical integration that the sales effort assumed a primary structural function, as one of capitalism's "decisive nerve centers."

In sum, the core actors and activities that drove the processes of materialization and, thus the (de)stabilization of goods and services, were first institutionalized as elements of standard business practice during the material expansionary phase of the U.S.-led systemic cycle of accumulation, Arrighi's "long twentieth century." The routinization and professionalization of the sales effort were achieved most directly through the formation of marketing and advertising firms themselves, specializing in the these activities as their primary line of activity, and through the establishment of marketing, promotional and branding departments within the prototypical vertically-integrated corporation. Thus if we hope to uncover the socioeconomic dynamics that change the scale and scope of these processes of materialization we must understand the kinds of pressures to which the activities and agencies comprising the "sales effort" are subjected by the large-scale institutional and world-economic reorganization associated with the financial expansion.

\section{PART III: FINANCIALIZATION, (DE)MATERIALIZATION AND ABSTRACTION}

We have thus far sought to more systematically articulate and elaborate Jameson's rather underspecified assertion that the expanding volume of finance capital, or its growing importance as a source of accumulation, within the world-economy underpins or drives the fragmentation and increasing abstraction of postmodern culture. Following Jameson's own indication, we have looked to the increasing commercialization of culture and the growing importance of "aesthetic" or cultural innovation as a foundational source of this cultural shift. Narrowing our focus, we have then identified Slater's "processes of materialization" as one of the primary mechanisms generating cultural abstraction of this sort. The processes of materialization are what "stabilize" our understanding of what constitutes a good or service and the particular material "meaning" we attach to it through its presumed utility and function. By now, the processes of materialization are primarily the purview of firms specializing in advertising and branding as well as bureaus within larger firms charged with the same activities - all of them specializing in the sales effort.

As we have argued above, financialization is accompanied by - indeed reflects - the large-scale restructuring of the capitalist world-economy through organizational, institutional and political transformations. So, what happens to this "sales effort" as the comparatively cooperative, phase of Arrighi's material expansion gives way the increasingly zero-sum competition emblematic of financialization? To be sure, the sales effort certainly does not disappear or diminish with this shift, even if the prevailing world-economic conditions in the

\footnotetext{
${ }^{7}$ Baran and Sweezy would likely have also agreed with Slater's earlier contention that the basic activities associated with the process of materialization were by no means a novelty of the mid-twentieth century, given their assertion that salesmanship is in fact "... much older than capitalism as an economic and social order" (114-115).
} 


\section{JOURNAL OF WORLD-SYSTEMS RESEARCH}

material expansion are themselves fundamentally altered by the "financial turn." To the contrary, the sales effort has only intensified along with financialization. In commodity chain terms, the broadest shift associated with the financialization of the world-economy since the 1970s has been the widespread dis-integration and reconfiguration of formerly vertically integrated commodity chains. This has given rise to what the literature generally refers to as "buyer-driven" commodity chains. In these chains, lead firms coordinate and "drive" the organization of the commodity chain through contracting relationships, without taking a direct equity ownership stake in many of the links or nodes in the chain (Gereffi 1994). As such, the function of the sales effort has shifted away from an essential set of activities needed to stabilize a capitalist world-economy driven by large, multi-national, multi-divisional corporations, and toward a set of activities by which a growing number of firms compete, even more intensively, as their primary specialization and/or source of competitive advantage. This is a move from management of the total productive flow from initial inputs to final outputs toward, to re-work Harvey's (1990) phrase, increasingly "flexible specialization" in only a select few activities or commodity chain nodes.

The overarching trend produced by this dynamic has been the turn toward financial activities as a means of capital accumulation, yet it would be absurd to claim that the global division of labor itself becomes more financial, post-industrial, or abstract/intangible as a whole. Indeed, the total volume of commodity manufacturing output at the world level has increased during this phase of financialization even if, at the same time, manufacturing and industrial activities have not been (see figures on world manufacturing value-added in Amsden 2003, Arrighi et. al. 2003; Krippner 2005). In Arrighi's scheme, the dynamics of financialization are not simply those of money capital in circulation. The issue is instead one of reorganization of the geographical distribution of global commodity chains, as well as the leading sectors of capital accumulation. And, as commodity markets grow increasingly competitive at the close of the material expansion, we can anticipate three general strategies for firms, whether pursued alone or - more realistically - in conjunction with each other. ${ }^{8}$

Firstly, firms might remove themselves as much as possible from commodity production chains entirely, shifting capital toward directly financial sources of profit and accumulation. Evidence for this shift is apparent from Krippner's (2005) analysis of the financialization of the U.S. economy. Krippner finds not only the growing weight of the financial sector within the overall accumulation of profits in the U.S., but, just as important, a marked rise in the significance of finance-related activities for non-financial firms. Put differently, the result of this first strategy is a shift toward financial means of accumulation by firms that historically specialized in commodity chains organized primarily around productive activities. This strategy is reflected by non-financial firm expanding their acquisition of financial assets, expanding the scope and scale of their existing financial subsidiaries, or acquiring new, finance-centered subsidiaries (Crotty 2005: 104). For instance, General Motors - the prototypical example of the vertically-integrated, commodity-production chain - and the degree to which this firm has leaned more heavily on its own finance subsidiary (GMAC) to generate profits for the entire organization - not just on automobile loans but a full array of financial instruments and

\footnotetext{
${ }^{8}$ Please note that the following types of firm-level responses are not intended to be comprehensive summaries of empirical demonstration of these strategies but rather illustrative sketches in the service of our broader argument.
} 
investments (including a heavy investment-turned-loss in the American "subprime" mortgage market) (Andrews 2009).

Secondly, firms might retain some engagement with manufacturing commodity chains, but a more selective one guided by the value-added within these nodes. As it happens, this has generally pushed firms away from specialization in productive activities through vertical integration, resulting in precisely the dynamic captured by existing GCC studies that trace a large-scale shift into marketing and branding activities in a number of different industries. The GCC research literature, amongst many others, is rife with empirical illustrations of this strategy (Bair and Gereffi 2001; Coe 2004; Coe and Hess 2005; Dolan, Humphrey and Harris-Pascal 1999; Gereffi 1999; Hughes 2000, 2007; Hughes, Wrigley and Buttle 2008; Jernigan 2000; Klein 2000; Korzeniewicz 1994; Pratt 2008). The sport-oriented apparel, equipment and footwear firm Nike typifies this strategy. As a so-called "manufacturer without (company owned) factories" Nike epitomizes this specialization in the sales effort - leaving actual production and sourcing activities to a variety of sub-contractors in which Nike has no equity stake or direct ownership control. Nike thus specializes in design work, branding, marketing, lifestyle construction and the like, benefitting from increasing competition amongst sub-contracted suppliers in the form of lower production costs, little need for coordination in supply of materials and manufacturing, and greater flexibility (Hollister 2008; Korzeniewicz 1994; Strasser 1993).

The third strategy is a move to create new areas of activity - be they new product lines or incorporation of new geographical areas. This strategy might rely on the creation of new commodity chains outright, or the "colonization" reorganization of existing but under-exploited commodity chains. ${ }^{9}$ My own research (2005) on the creation and continued evolution of an increasingly commercialized world soccer economy since the early 1970 s provides some illustration of this strategy. After 1970, a number of major professional sports which had until then been only partially, or much less intensively, commodified were transformed by a wave of commercialization. This wave was often facilitated by an overlapping network of agents and firms who realized it was both possible (primarily because of media deregulation and expansion) and attractive (because there were comparatively few competitive pressures within the global sport economy) to valorize sporting activities and organizations (Aris 1990; Smit 2007, 2008; Sugden and Tomlinson 1998, 2003). In almost every case, the reconfiguration of these sporting commodity chains depended on linking them more directly to existing broadcast media commodity chains, unlocking new sources of revenue and profits within the professional sport economy. What is more, a number of the central actors in driving the commercialization of soccer (most notably, Adidas executive Horst Dassler) themselves came from backgrounds in the kinds of athletic fashion apparel and footwear firms that so strongly exemplify the "buyer-driven" commodity chain model (Andrews 2001).

What is most interesting in the light of our focus on the "cultural economy" is the centrality of the mass media along with the sales efforts of advertising, branding and marketing within all three strategies. What is more, it is not difficult to see the potentially self-reinforcing nature of these strategies - how the expansion of some of these activities can, at the aggregate level, call forth further investment and activity within the others. All of these strategies can deepen and intensify the sales effort. The "virtuous circle" here is logically straightforward: the

\footnotetext{
${ }^{9}$ In Slater's terms, we would see this as the market "materialization" of previously ignored spheres of social activity.
} 


\section{JOURNAL OF WORLD-SYSTEMS RESEARCH}

more that firms of all sorts pursue financial forms of expansion, the more that capital is available and, in fact, in need of new investment opportunities. As leading firms in a variety of productive industries specialize more narrowly in the sales effort alone (Nike, Reebok and other footwear design/brand companies, for instance), competition within the sales effort activities intensifies. Increased competition within the sales effort fosters increasing innovations within this domain, attracting or demanding even further investment in the sales effort.

This kind of commercial "cultural" work - the branding, promotional, and advertising activities of the sales effort - further encourages an expansion in the need for venues for this work, deepening the demand for media outlets of various sorts and the innovative and novel use of mass media formats both old and new. Finally, media commodity chains - in part from their growing significance following from the pressures elaborated above - themselves can feature within the third firm-level strategy identified earlier: that is within the move toward previously under-exploited or ignored lines of accumulation. In a context where large multi-divisional corporations are seeking new lines of activity and accumulation (having retracted or lessened their involvement in material commodity chains), nodes within already-established mass media commodity chains (e.g. broadcast networks, talent agencies, movie studios) begin to appear as potentially enticing acquisitions themselves.

It is in the conjoint operation of all these factors - that is, the shifting of firm-level resources and business strategies toward new and/or alternative lines of activity, a growing reliance on the sales effort within these, specialization within the sales effort itself - that we can locate the intensification of competition as well as expansion of scale in the processes of materialization. And as the sales effort in its various forms has expanded (Dawson 2004), this has ultimately only further intensified the processes of materialization and, by turn, our perception of the (im)materiality of socio-economic life and the predominance of cultural abstraction.

\section{CONCLUDING REMARKS \& IMPLICATIONS}

My aim in this essay has not been to "prove" these various contentions but rather to sketch out how they might be put together in the service of a broader argument linking financialization to cultural transformation. The model I have advanced toward this end begins from Jameson's rather nebulous linking of finance capital (more specifically, Arrighi's financialization) to a "cultural turn" within the socio-economic sphere. This turn has allegedly propelled the fragmentation and abstraction of contemporary cultural representation. I have advanced or solidified Jameson's contention in two main ways. First, I have reiterated and elaborated the conceptual underpinnings of Arrighi's framework, upon which Jameson constructs his interpretation of the finance capital and culture link. Here I have, in particular, emphasized the dynamics of world-economic restructuring that are both cause and consequence of financialization.

Secondly, I have specified a set of activities - Slater's processes of materialization through which socio-economic restructuring can be linked to the commercial cultural transformations that Jameson nods toward as the "source" of postmodern abstraction. Putting these two insights together, I have argued that the restructuring and reorganization that is part and parcel of financialization. Moreover, as illuminated by the commodity chain heuristic, financialization has intensified competition within the processes of materialization by 
repositioning their structural function for, and organizational housing within, business enterprises in this current era of financial expansion.

Of course, this argument alone is not sufficient to document such linkages and connections. Thus, returning to the original hope that this framework could help in more effectively articulating the efforts of scholars of the world-system and global political-economy with those of the cultural studies and critical theory domains, I believe there are different lessons for each. In the case of the global commodity chains literature, the issue seems to be seeing the forest for the trees. On the one hand, we have an impressive accumulation of empirically-rich studies of specific commodity chains, many arriving at the conclusion that "culture" increasingly matters for competitive advantage. On the other hand, the accomplishments of empirical depth underscore the need for a comprehensive cross-chain (or, aggregated chain) meta-analysis. In other words, a step back from the intensely concrete and empirically rich "within" commodity chain focus might reveal broader "sectoral" (or "across" chain) trends that could help to direct future commodity chain research toward a more systematic, less atomized, account of contemporary socio-economic change. For instance, the "sectoral" connections we have just discussed, connecting the sales effort activities in a host of production-centered global commodity chains to commercial mass-media commodity chains, is unlikely to be illuminated by digging deeper empirically into either set of commodity chains; collecting detailed analyses of each of the trees still won't give us an adequate account of how the forest operates as a whole. Hopefully this essay demonstrates, at least in outline form, how this inter-chain aggregation, or sectoral analysis, might be accomplished for our particular concerns.

Likewise, Arrighi's world-historical analysis can bring to the study of commercialized popular culture, or the cultural studies project more broadly, a more structured analytical and methodological framework, as well as a deeper range of historical evidence. Bringing this historical framework to bear on the concerns of cultural studies is intended to strengthen the utility of the latter - most significantly by hewing to Arrighi's Three Questions: What is cumulative? What is cyclical? And what is truly new about contemporary cultural change? In this respect, the world-historical analysis above undermines the hyperbole of much of the cultural economy discourse - at least in so far as such analysis asserts the profound novelty of contemporary developments. Yet, it nonetheless reinforces and amplifies the more nuanced notion that marketing, advertising, branding, and the "sales effort" more generally, has changed in important ways since the 1970 s. The nature of such changes can only be elucidated through historical analysis of the sort described above, so I would hope that the cultural studies project and those concerned with the commercialization of culture more broadly - might engage such analysis more vigorously.

\section{ACKNOWLEDGEMENTS}

Many thanks to Jason W. Moore and an anonymous reviewer at JWSR for extensive, insightful and useful comments. Giovanni Arrighi also provided comments on a much earlier version. This work was supported in part by the James Madison University Program of Grants for Faculty Educational Leaves. 


\section{JOURNAL OF WORLD-SYSTEMS RESEARCH}

\section{REFERENCES}

Amsden, Alice. 2003. "Comment: Good-Bye Dependency Theory, Hello Dependency Theory." Studies in Comparative International Development 38(1): 32-38.

Andrews, David L. 2001. "Sport." Pp. 131-162 in Culture Works: The Political Economy of Culture, edited by Richard Maxwell. Minneapolis, MN: University of Minnesota Press.

Andrews, Edmund L. 2009, May 21. "Treasury Department is Said to Plan Second Bailout for GMAC." New York Times, accessed online 3/4/2010.

Aris, Stephen. 1990. Sportsbiz: Inside the Sports Business. London: Hutchinson.

Arrighi, Giovanni. 1994. The Long Twentieth Century: Money, Power, and the Origins of Our Times. London: Verso.

2007. Adam Smith in Beijing. London: Verso.

Arrighi, Giovanni, Kenneth Barr, et al. 1999. "The Transformation of Business Enterprise." Pp. 97-150 in Chaos and Governance in the Modern World System, Giovanni Arrighi and Beverly J. Silver. Minneapolis, MN: University of Minnesota Press.

Arrighi, Giovanni and Beverly J. Silver. 1999. Chaos and Governance in the Modern World System. Minneapolis, MN: University of Minnesota Press.

Arrighi, Giovanni, Beverly J. Silver and Benjamin D. Brewer. 2003. "Response to Alice Amsden." Studies in Comparative International Development 38(1): 39-42.

Aspers, Patrick. 2010. "Using Design for Upgrading in the Fashion Industry." Journal of Economic Geography 10: 189-207.

Bair, Jennifer and Gary Gereffi. 2001. "Local Clusters in Global Chains: The Causes and Consequences of Export Dynamism in Torreon's Blue Jean Industry." World Development 29: 1885-1903.

Baran, Paul A. and Paul M. Sweezy. 1966. Monopoly Capital: An Essay on the American Economic and Social Order. New York: Monthly Review Press.

Bell, Daniel. 1973. The Coming of Post-Industrial Society. New York: Basic Books.

Brewer, Benjamin D. 2005. Switching Fields: The World Soccer Economy in an Era of Globalization. Doctoral Dissertation, Department of Sociology, Johns Hopkins University.

Castells, Manuel. 2000a. The Rise of the Network Society (Second Edition). Oxford: Blackwell. . 2000b. End of Millenium (Second Edition). Oxford: Blackwell. . 2004. The Power of Identity (Second Edition). Oxford, Blackwell.

Coe, Neil M. 2004. "The Internationalisation/Globalisation of Retailing: Towards an Economic Geographical Research Agenda." Environment and Planning A 36(9): 1571-1594.

Coe, Neil M. and Martin Hess. 2005. "The Internationalization of Retailing: Implications for Supply Network Restructuring in East Asia and Eastern Europe." Journal of Economic Geography 5(4): 449-473.

Crotty, James. 2005. "The Neoliberal Paradox: The Impact of Destructive Product Market Competition and 'Modern' Financial Markets on Nonfinancial Corporation Performance in the Neoliberal Era." Pp. 77-110 in Financialization and the World Economy, edited by Gerald A. Epstein. London: Edward Elgar.

Dawson, Michael. 2004. The Consumer Trap: Big Business Marketing in American Life. Chicago: University of Illinois Press.

DeBord, Guy. 1995 [1967]. The Society of the Spectacle. London: Zone Books. 
Dolan, Catherine, John Humphrey, and Carla Harris-Pascal. 1999. "Horticulture Commodity Chains: The Impact of the UK Market on the African Fresh Vegetable Industry." University of Sussex Institute of Development Studies Working Paper \#96.

Ewen, Stuart. 2001. Captains of Consciousness: Advertising and the Social Roots of the Consumer Culture (25th Anniversary Edition). New York: Basic Books.

Gereffi, Gary, John Humphrey, Raphael Kaplinsky and Timothy J. Sturgeon. 2001. 'Introduction: Globalisation, Value Chains and Development." Pp. 1-8 in IDS Bulletin: The Value of Value Chains, edited by Gary Gereffi and Raphael Kaplinsky. Sussex, UK: Sussex University Institute of Development Studies.

Gereffi, Gary. 1994. "The Organization of Buyer-Driven Global Commodity Chains: How US Retailers Shape Overseas Production Networks." Pp. 95-122 in Commodity Chains and Global Capitalism, edited by Gary Gereffi and Miguel Korzeniewicz. Westport, CT: Praeger.

1999. "International Trade and Industrial Upgrading in the Apparel Commodity Chain." Journal of International Economics 48: 37-70.

2001. "Beyond the Producer-driven/Buyer-driven Dichotomy: The Evolution of Global Value Chains in the Internet Era." Pp. 30-40 in IDS Bulletin: The Value of Value Chains, edited by Gary Gereffi and Raphael Kaplinsky. Sussex, UK: Sussex University Institute of Development Studies.

Harvey, David. 1990. The Condition of Postmodernity. Cambridge, MA: Blackwell.

Hollister, Geoff. 2008. Out of Nowhere: the Inside Story of How Nike Marketed the Culture of Running. Meyer \& Meyer Sport.

Homer, Sean. 2002. "Fredric Jameson." Pp. 180-188 in Postmodernism: The Key Figures, edited by Hans Bertens and Joseph Natoli. London: Blackwell Publishers.

Hughes, Alex. 2000. "Retailers, Knowledges and Changing Commodity Networks: The Case of the Cut Flower Trade." Geoforum 31:175-190.

. 2007. "Geographies of Exchange and Circulation: Flows and Networks of Knowledgeable Capitalism." Progress in Human Geography 31(4): 527-535.

Hughes, Alex, Neil Wrigley and Martin Buttle. 2008. "Global Production Networks, Ethical Campaigning, and the Embeddedness of Responsible Governance." Journal of Economic Geography 8(3): 345-367.

Humphrey, John and Hubert Schmitz. 2001. "Governance in Global Value Chains." Pp. 19-29 in IDS Bulletin: The Value of Value Chains, edited by Gary Gereffi and Raphael Kaplinsky. Sussex, UK: Institute of Development Studies at Sussex.

Jameson, Fredric. 1984. "Postmodernism, or, The Cultural Logic of Late Capitalism." New Left Review n. 146: 59-92.

. 1991. Postmodernism, or, The Cultural Logic of Late Capitalism. Durham, NC: Duke University Press.

1998. "Culture and Finance Capital."Pp. 136-161 in The Cultural Turn: Selected Writings on the Postmodern 1983-1998. New York: Verso Press.

Jernigan, David H. 2000. "Applying Commodity Chain Analysis to Changing Modes of Alcohol Supply in a Developing Country." Addiction 95 (Supplement 4):S465-S475. 


\section{JOURNAL OF WORLD-SYSTEMS RESEARCH}

Korzeniewicz, Miguel. 1994. "Commodity Chains and Marketing Strategies: Nike and Global Athletic Footwear Industry." Pp. 247-265 in Commodity Chains and Global Capitalism, edited by Gary Gereffi and Miguel Korzeniewicz. Westport, CT: Praeger.

Kaplinsky, Raphael. 2005. Globalization, Poverty and Inequality: Between a Rock and a Hard Place. Malden, MA: Polity Press.

Klein, Naomi. 2000. No Logo. New York: Picador.

Krippner, Greta R. 2005. "The Financialization of the American Economy." Socio-Economic Review 3: 173-208.

Lash, Scott and John. 1987. The End of Organized Capitalism. Madison, WI: University of Wisconsin Press. . 1994. Economies of Signs and Space. London: Sage Publications.

McMichael, Philip. 2007. Development and Social Change: A Global Perspective. New York: Pine Forge Press.

Ohmann, Richard. 1996. Selling Culture: Magazines, Markets, and Class at the Turn of the Century. London: Verso.

Pope, Daniel. 1983. The Making of Modern Advertising. New York: Basic Books.

Poster, Mark. 1990. The Mode of Information: Poststructuralism and Social Context. Chicago, IL: University of Chicago Press.

Pratt, Andy C. 2008. "Cultural Commodity Chains, Cultural Clusters, or Cultural Production Chains?" Growth and Change 39(1): 95-103.

Roberts, Adam. 2000. Fredric Jameson. London: Routledge.

Slater, Don. 2002. "Markets, Materiality and the "New Economy." Pp. 95-114 in Market Relations and the Competitive Process, edited by Stan Metcalfe and Alan Warde. Manchester, UK: Manchester University Press.

Smit, Barbara. 2007. Pitch Invasion: 'Adidas', 'Puma' and the Making of Modern Sport. New York: Penguin.

. 2008. Sneaker Wars: The Enemy Brothers Who Founded Adidas and Puma and the Family Feud That Forever Changed the Business of Sport. New York: Ecco Publishers.

Strasser, J.B. 1993. Swoosh: The Unauthorized Story of Nike and the Men Who Played There. New York: Harper Paperbacks.

Sugden, John and Alan Tomlinson. 1998. FIFA and the Contest for World Football. Cambridge, UK: Polity Press.

. 2003. Badfellas: FIFA Family at War. Edinburgh, UK: Mainstream Publishing.

Webster, Frank. 2002. Theories of the Information Society: Second Edition. New York: Routledge. 